\title{
LOS GRUPOS NÓMADES DE LA PATAGONIA Y EL CHACO EN EL SIGLO XVIII: IDENTIDADES, ESPACIOS, MOVIMIENTOS Y RECURSOS ECONÓMICOS ANTE LA SITUACIÓN DE CONTACTO. UNA REFLEXIÓN COMPARATIVA
}

\author{
NOMADIC GROUPS OF THE PATAGONIA AND CHACO REGIONS \\ IN THE XVIII CENTURY: IDENTITIES, SPACES, MOVEMENTS \\ AND ECONOMIC RESOURCES IN THE FACE OF EUROPEAN CONTACT. \\ A COMPARATIVE REFLECTION
}

Lidia R. Nacuzzi ${ }^{1}$

\begin{abstract}
Se propone en este trabajo una reflexión comparativa acerca de los grupos indígenas de Pampa-Patagonia norte y los del Chaco austral oriental y los cambios que, para el siglo XVIII, habían introducido en sus formas tradicionales de intercambios, movilidad, adquisición de recursos económicos y explotación de recursos naturales, como consecuencia del contacto con europeos. Esto aportará nuevos datos para la región patagónica y, para el Chaco austral, planteará en otros términos algunas cuestiones sobre las cuales el debate parece clausurado, como son la identificación de grupos étnicos, el papel de los bienes europeos en su economía y la verdadera dimensión del nomadismo.
\end{abstract}

Palabras claves: Pampa-Patagonia, Chaco, relaciones interétnicas, frontera.

This paper proposes a comparative consideration of the indigenous groups of Pampa-Patagonia and southern Chaco. By the XVIII century said groups introduced changes in their traditional ways of trading, mobility, acquisition of economic resources and exploitation of natural resources, due to European contact. This approach not only provides new data on the Patagonian and southern Chaco regions, it also allows review of issues on which debate seems to have ended, such us: ethnic group identification, the role of European goods in the economy and the true dimension of nomadism.

Key words: Pampa, Patagonia, Chaco, interethnic relationships, frontier.

En la historia de la "conquista y colonización del nuevo mundo", en el extremo sur del continente, el siglo XVIII fue un período destacable por varios aspectos. Por un lado, la Corona española implementó nuevas políticas para fortalecer su autoridad, lograr un mayor control económico y social, incrementar sus ingresos y ejercer una defensa más eficaz de sus fronteras. Por el otro, en el mundo indígena se vieron plasmados y fortalecidos una serie de cambios que devinieron en profundas transformaciones económicas, primero y espaciales y políticas más tarde. Entre las cuestiones que sirvieron como disparadoras de estos cambios, se encuentran (en regiones como Pampa-Patagonia) el control de una buena cantidad de cabezas de ganado caballar y vacuno y (en otras y sumado a lo anterior, como el Chaco austral orien- tal) el establecimiento de pueblos de reducción. En ambos casos, también se había incrementado, de manera pacífica o violenta, el contacto con los españoles e hispanocriollos y sus pueblos y ciudades. Los pueblos indígenas que no habían podido ser sometidos al control del estado colonial hasta ese momento, debido precisamente a su condición de nómades, para el siglo XVIII se habían relacionado exitosamente con las colonias españolas y -ampliando su radio de acción- con más pueblos indígenas, habían reformulado sus circuitos económicos en razón de estas nuevas relaciones interétnicas, incorporando nuevos bienes y replanteando sus pautas de movilidad, los espacios que ocupaban y la obtención de recursos económicos.

El escenario de estos cambios fue un ámbito de frontera, aunque no necesariamente se trató de

1 CONICET/Universidad de Buenos Aires, Facultad de Filosofía y Letras. Puán 480. 1406 Ciudad de Buenos Aires, Argentina. lidianacuzzi@yahoo.com.ar 
situaciones desarrolladas de cara a una "línea de frontera" o una "franja fronteriza". Como veremos, predominaron las relaciones con lo que prefiero denominar enclaves fronterizos, ya fuera que se tratara de instalaciones explícitamente defensivas como el Fuerte del Río Negro en el norte de Patagonia o pueblos de reducción a cargo de la Compañía de Jesús en el litoral del río Paraná. Estos enclaves tenían la característica de no participar de una línea de frontera en avance y protegiendo a una región poblada más o menos densamente por criollos, mestizos, indios y milicianos. Eran, en cambio, lugares totalmente aislados -como el caso del fuerte mencionado- o pueblos de indios que habían sido creados -como fue el caso de las misiones- para proteger a una incipiente ciudad cercana del avance de otros indígenas de la región. De cualquier manera, estaban en una situación diferente que la que se daba en fronteras como la del sur de Buenos Aires o la del occidente del Chaco.

También en este último caso (lugares aislados o pueblos de reducción creados como cordón defensivo), el contacto no se dio únicamente provocado desde y por el grupo colonizador. Los grupos indígenas fueron protagonistas muy activos: adoptaron y/o adaptaron diversos bienes, negociaron, intercambiaron, brindaron y exigieron servicios a "los blancos" en una relación bastante igualitaria, lo que los transformó en protagonistas no secundarios de ese contacto. Los pueblos de los que se trata no estuvieron en una continua situación de conflicto. Aun los reducidos -como veremos- desarrollaron una manera de vivir en esa condición que se adaptaba a sus pautas anteriores y les permitía flexibilizar la inmovilidad que hubiera supuesto la vida en un pueblo de reducción. El concepto de contacto, en sus acepciones "directo" o "indirecto", acuñado por Wachtel (1978) fue retomado luego por diversos autores, para llegar a la propuesta de Pratt (1997:26) quien habla de "zona de contacto". En esas zonas tienen un papel destacado las dimensiones "interactivas y de improvisación" de los encuentros coloniales, con una "trabazón de prácticas" dentro de relaciones asimétricas en "insuperable conflicto" (en esta última apreciación difiero con la autora). Esas improvisaciones dieron lugar a la concepción de un espacio común de acción y comunicación entre indígenas y europeos en el sentido de lo que White (1991) ha definido como middle ground, o a "mes- tizajes" que van más allá de lo biológico (Gruzinski 1999). Rescato también la opinión de Quijada (2002:290), de enfocar a la aculturación "como juego de espejos", queriendo indicar que funcionó bidireccionalmente: "tanto indios como blancos incorporaron elementos de la otra sociedad" o "formas culturales ajenas que les eran convenientes" aunque persistiera la desconfianza mutua.

Se realizan aquí algunas reflexiones de carácter comparativo sobre poblaciones nativas de dos regiones vecinas pero que no han merecido aún un estudio de este tipo. Los grupos indígenas del norte de la Patagonia y la Pampa, como los del Chaco austral oriental, desarrollaron espacios de acción y comunicación con los europeos, incorporaron bienes de la otra sociedad, entrecruzaron sus prácticas e improvisaron formas de actuar e intervenir en diversas esferas de la vida social y política. En el oriente del Chaco austral, los jesuitas establecieron a partir de 1743 varias reducciones de indios mocovíes o abipones bajo la jurisdicción de las ciudades de Santa Fe o de Asunción. Por otra parte, los funcionarios españoles, temerosos de posibles desembarcos ingleses, enviaron expediciones a la costa patagónica para establecer allí cuatro fuertes, de los cuales el de Nuestra Señora del Carmen fundado en 1779 por Francisco de Viedma fue el único que prosperó. Antes del contacto estos grupos eran muy semejantes en ciertos aspectos y las estrategias que adoptaron tras el contacto se ven también muy parecidas. A estos tópicos siempre se hizo referencia de manera general. Creemos que un repaso de los mismos con el ánimo de compararlos puede iluminar de manera diferente temas y problemas que por muy conocidos -o tal vez sólo por muy mencionadosparecen no requerir más análisis.

\section{EI Escenario y sus Habitantes}

El Chaco es una región con vegetación de bosques abiertos y estepas y, sobre las márgenes de los ríos, vegetación típica de la selva subtropical; los grupos indígenas supieron aprovechar la vegetación exuberante para refugiarse, aunque también recorrían las extensas llanuras semidesérticas y ocupaban los bosques abiertos y los montes, que prometían mejores recursos para la caza, la pesca y la recolección. Tenían una gran variedad de animales silvestres disponibles para la caza, de los que aprovechaban mayormente: ciervos, 
tigres, jabalíes, yacarés, puercoespines; también había variedad de peces y especies vegetales aprovechables para diversos usos.

La región pampeano patagónica es predominantemente mucho más árida y seca, con relieve de mesetas y vegetación de monte; cuando aparecen ojos de agua, se conforman "mallines" en algunos puntos de las extensas planicies (espacios acotados con abundante agua y pastos muy tiernos); sólo en la región vecina a la Cordillera hay bosques y terrenos más fértiles que permitieron algunos cultivos. El guanaco y el ñandú eran las únicas presas grandes disponibles para la caza y las especies vegetales eran escasas aunque aprovechadas intensivamente por los indios como alimento, materia prima y tinturas.

En ambas regiones los estudios de la etnografía clásica (me refiero a los que se realizaron hasta la década de 1980) identificaron a numerosos grupos étnicos, aunque muchas veces esa precisión era sólo nominal, puesto que a la hora de describir las características de estos grupos, se lo hacía bajo un rótulo amplio: "los pueblos del Chaco" (Susnik 1971, 1981) o "los patagones" (Canals Frau 1973). Hubo, sin embargo, alguna diferencia provocada por el desarrollo de las investigaciones etnográficas, el contexto académico en que se produjeron esos trabajos y las disputas entre investigadores (aspectos que fueron estudiados en detalle para Pampa-Patagonia, ver Nacuzzi 2002, 2005). En Patagonia los diferentes nombres tendieron a englobarse bajo dos rótulos dominantes: "tehuelches" o "patagones" y "mapuches" o "araucanos" (Casamiquela 1985; Escalada 1949; entre otros). En el Chaco se mantuvieron las numerosas designaciones desde la primera clasificación de Kersten (1968) realizada en 1905: abipones, mocovíes, tobas, mbayás y payaguás -de una familia lingüística- y lules y vilelas -de otra-, con algunos agregados según los autores (Canals Frau 1973; Saeger 2000; Susnik 1971; entre otros). Estos son los rótulos en los que la mayoría de los autores coincide, aunque falta un estudio de cómo pasaron de un autor a otro que pueda identificar las copias acríticas y/o las argumentaciones que podrían encerrar, como en Pampa y Patagonia, solapadas e inútiles disputas por mantener ciertos rótulos. Según esa bibliografía, mocovíes y abipones habrían pertenecido a la familia lingüística Guaycurú y muchas veces, bajo ese rótulo, aparecen descripciones que no los diferencian. En am- bas regiones se reconoce la bipartición que señala a grupos nómades por un lado, como los tehuelches, abipones, tobas y mocovíes y, por el otro, a grupos más sedentarios y con prácticas agrícolas como los mapuches, lules y vilelas.

Entre los especialistas que se han dedicado al Chaco, hay algunos que prefieren usar un nombre menos específico aún, como "los chaqueños", en oposición a "la sociedad hispano-criolla" y definirlos por esa misma oposición (Santamaría 2000; entre otros), sobre todo porque se han referido a cuestiones económicas, donde la adscripción étnica parece no pesar tanto.

En las regiones propuestas se pasó de la mencionada enumeración de una gran cantidad de nombres étnicos -aunque con escasas diferencias formales entre unos y otros a la hora de describir a los grupos-a evitar mencionar esas subdivisiones en trabajos más recientes que se ocupaban de aspectos económicos, políticos, ceremoniales o sociales. Aunque es un panorama farragoso y las fuentes son elusivas, todavía estamos en deuda con el estudio de las identidades étnicas y los procesos de etnogénesis y reconfiguración étnica que impulsó el contacto con los europeos. Además, entre los estudios más recientes, el perfil de nómades de los grupos y el tipo de bienes de la sociedad blanca que incorporaron predeterminaron algunas explicaciones que habrá que explorar más profundamente en trabajos futuros. Por otra parte, en los estudios sobre Patagonia y por lo menos hasta la década de 1980, hubo una tendencia a considerar datos que brindaban fuentes de diversos períodos y lugares como válidos para describir a "los tehuelches" o "los araucanos" de cualquier momento del período de contacto y de cualquier lugar del extenso paisaje patagónico. Parece que esa tendencia sigue utilizándose para estudiar la economía indígena del extenso "gran Chaco argentino" (Paz 2003) con fuentes tanto jesuíticas como de la "pacificación" militar del Chaco (1884-1885).

El caso de los tehuelches del norte de la Patagonia fue estudiado hace ya unos años (Nacuzzi 1998), mostrando cómo los rótulos usados por los primeros exploradores y viajeros (tehuelches, aucas y pampas) fueron adaptándose y convirtiéndose en nombres étnicos que no conllevaban en casi ningún caso un reconocimiento de identidad por parte de los grupos, además de otros temas como los territorios de cada grupo, sus movimientos 
y relaciones interétnicas. También para algunos de los grupos que habitaron el Chaco austral disponemos ahora de trabajos más pormenorizados: en recientes investigaciones se ha comenzado a estudiar a los denominados abipones (Lucaioli 2005) y mocovíes (Nesis 2005), con fuentes predominantemente jesuíticas (Dobrizhoffer 1968-1969 y Paucke 1943-1944, respectivamente). En minuciosos análisis de las fuentes y una importante compulsa de la bibliografía disponible estas autoras no han encontrado que los nombres mencionados para el Chaco se refirieran a autoadscripciones de los grupos, aunque pueden describir que se habría tratado de identidades impuestas (Nacuzzi 1998) o procesos de construcción e interdigitación (Boccara 2000) que llevaron a que -dado que los otros los designaban así- ellos se reconocieran a sí mismos como abipones y mocovíes, fenómeno que ocurrió también con los pampas y aucas del norte de la Patagonia.

\section{Los Grupos, sus Territorios y sus Movimientos}

Los tehuelches ocupaban la región patagónica desde el extremo sur hasta, por lo menos, el río Colorado al norte, donde comenzaba las región en la que se habían instalado los aucas o mapuches: la pampa, a la que algunos autores (Sánchez Labrador 1936) han considerado acertadamente como una "tierra franca" a donde muchos grupos indígenas de diferentes regiones concurrían para intercambiar bienes. Aucas (o mapuches) y pampas eran rótulos que se confundían habitualmente en la nomenclatura de los europeos de los primeros contactos. Los abipones se encontraban en la zona del Chaco delimitada al suroeste por el río Salado, al norte por el río Bermejo y al este por los ríos Paraná y Paraguay, concentrándose mayormente en la zona austral cercana a las ciudades de Santa Fe y Corrientes. Los mocovíes estaban en el extremo sur de esta región, compartiendo sus territorios con los abipones (Figura 1).

Estos grupos reformularon sus circuitos económicos haciéndolos más extensos y/o modificándolos para obtener bienes ofrecidos o requeridos por otros grupos (ya fueran indios o españoles), lo que implicó modificar sus pautas de movilidad que, en general, estaban adaptadas a espacios más cortos y eran estacionales. En el siglo XVIII se alargaron las distancias y comenzaron a funcionar en torno al requerimiento de las colonias. Esto no hubiera sido posible sin la incorporación previa del caballo a sus vidas, tema que trataremos en detalle más adelante.

Entre los tehuelches, los del norte disponían de una mayor cantidad de caballos que les permitían movilizarse con mucha facilidad hasta los campos del sur de Buenos Aires o hacia la región cordillerana (Boschín y Nacuzzi 1979). Esto no quiere decir que hayan ampliado los territorios que consideraban como propios; éstos se mantuvieron en espacios acotados e identificados con los nombres de sus caciques. Así, por ejemplo, en la "Tierra de las Manzanas" estaba la gente del cacique Chulilaquin, en las cercanías de la desembocadura del río Negro los del cacique Negro, en el río Colorado el cacique Uzel, en las sierras de la Ventana el cacique Calpisqui, en las Salinas los caciques Alcaluan y Katruen, etc. (Nacuzzi 1998:159-162).

Para los abipones y mocovíes no tenemos tal grado de detalle sobre los espacios de cada cacique. Sin embargo, la información sobre estos grupos permite reconstruir un probable ciclo anual y, de esa forma, reforzar los indicios de la existencia de tales movimientos entre los de Patagonia (Nacuzzi 1991), región para la cual teníamos datos sobre estos ítems recién para el siglo posterior, brindados por el viajero G. Musters (1979). Lucaioli y Nesis (2005) afirman que "La movilidad espacial y territorial permitía a los grupos indígenas el despliegue de un determinado tipo de producción así como también la activación de un ciclo ritual anual [...] brindando oportunidades para el establecimiento de alianzas, matrimonios, enfrentamientos y celebraciones". Además, sabemos que los mocovíes delimitaban muy bien los parajes de sus campamentos base con altos mojones donde colgaban las cabezas de sus enemigos (Nesis 2005) y que, tanto ellos como los abipones, tenían una amplia movilidad gracias al caballo que usaban en partidas de caza, malones (apropiación violenta de ganado) y viajes de intercambio, funcionando -en estos aspectos- de manera similar a los grupos de Patagonia (Lucaioli 2005; Nesis 2005).

Para ambos grupos los accidentes geográficos importantes, como ríos anchos y caudalosos, actuaban como límites si no infranqueables, por lo menos de vecinos "no amigos". Esos ríos eran, entonces, demarcaciones territoriales entre grupos étnicos y/o parcialidades: el río Bermejo, el Salado, el Paraná en el Chaco (Lucaioli 2005; Nesis 


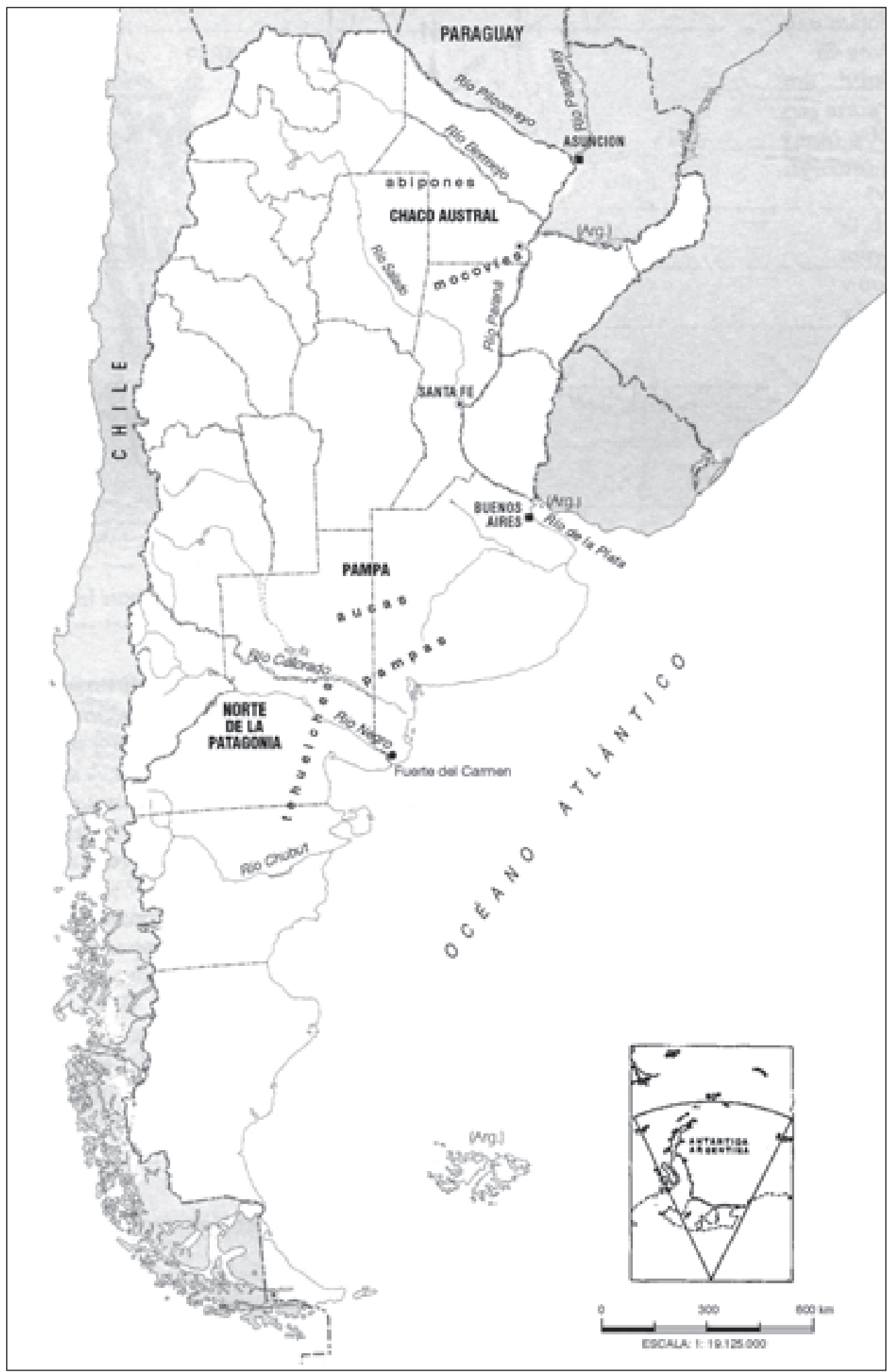

Figura 1. Ubicación de los grupos étnicos mencionados. Location of the ethnic groups. 
2005); los ríos Colorado y Chubut en Patagonia (Nacuzzi 1998). De todas maneras, estos ríos delimitaban amplias regiones por las que era posible que los grupos se desplazaran. Esas posibilidades de desplazamiento contribuyeron para que, tanto a los grupos del Chaco como a los de Patagonia, la literatura tradicional les atribuyera extensos territorios como ámbito habitual donde se establecían aleatoriamente, lo cual estuvo asociado, también, al prejuicio de "grupos errantes" que "vagaban en busca de la caza" para sustentarse. Hay dos supuestos fuertemente arraigados en la literatura etnográfica: (1) que los grupos cazadores recolectores limitaban sus actividades económicas a la subsistencia (Susnik 1981; Vignati 1941), y (2) que sus movimientos estaban condicionados por el medio ambiente: "ocuparon las comarcas preferidas por los avestruces o guanacos" (Escalada 1949:11), "se verían 'forzados' a una constante movilidad que les permitiría un mejor aprovechamiento de los recursos de la región" (Paz 2003:378). Esto no era tan simple.

Se ha discutido ampliamente la cuestión del nomadismo y los prejuicios que se enlazan al concepto de "pueblo nómade" para los tehuelches de Patagonia (Nacuzzi 1991): (1) que son exclusivamente cazadores (lo que oscurece otras actividades económicas muy importantes para el grupo, como la recolección de especies vegetales y su procesamiento para almacenar harinas, por ejemplo), (2) que son "salvajes", por no practicar la agricultura ni formar pueblos y (3) que no programan sus movimientos ni sus vidas, ni tienen un "estilo de vida civilizado". Debemos recordar que los grupos de Patagonia nunca pudieron ser reducidos y los del Chaco, aun viviendo en pueblos de reducción, no cumplían con el ideal de autoabastecimiento por medio de la agricultura como sucedía en los pueblos guaraníes, "las misiones" por antonomasia. Unos y otros siguieron siendo considerados como "no civilizados" por los misioneros y la literatura etnográfica. Sin embargo, los pueblos mocovíes adoptaron prácticas agrícolas y hortícolas, sembrando trigo y cuidando árboles frutales; aunque es posible que estas novedades se hayan visto deslucidas porque los misioneros tenían que compensar a los grupos que participaban de la cosecha con un permiso para salir a cazar por el mismo tiempo que les hubiera demandado esa actividad (Nesis 2005). Entre estos grupos también se menciona el cultivo de algodón en un volumen que alcanzaba para confeccionar la vestimenta de la gente que habitaba en la reducción. Otra novedad introducida en las reducciones fue la cría de ovejas y las actividades que conllevaba su explotación: las mujeres aprendieron a esquilar, hilar, teñir y tejer mantas o alfombras que pudieron enviarse a mercados como el de Asunción en un número considerable de piezas (Paucke 1943). La atención de los rebaños debió implicar una reducción en las pautas de movilidad del grupo, aunque la caza y la recolección continuaron siendo importantes actividades complementarias (Nesis 2005).

Entre tehuelches y abipones, en cambio, la adopción de bienes europeos estuvo más centrada en el ganado vacuno y caballar que no requería disminuir la movilidad de los grupos. En realidad, ellos acentuaron sus desplazamientos para obtener y trasladar ganado aunque a veces ese ganado les era proporcionado en el fuerte o en la misión a cambio de protección implícita o explícita. Pero la mayor cantidad de ese ganado era obtenida en expediciones de saqueo o sangrientos malones sobre los pueblos de la región de Buenos Aires o Asunción (Lucaioli 2005; Nacuzzi 1998; entre otros. Nacuzzi (1991) pudo identificar entre los tehuelches del siglo XIX distintos tipos de "paraderos" que también parecen encontrarse entre abipones y mocovíes del siglo XVIII, sustentando, como ya expresamos, el supuesto de una larga tradición en las formas de uso del espacio: (a) el campamento base, asentamiento que duraba varios meses y donde muchas veces quedaban las mujeres, los ancianos y los niños mientras los hombres salían en partidas de caza o de comercio de duración variable (Dobrizhoffer 1969:17; Musters 1979:303; Schmid 1964:28); (b) los asentamientos próximos en áreas de aprovisionamiento, en las que abundaba algún tipo de presa de caza (como el guanaco) o de frutos recolectables; estas áreas se visitaban en la temporada adecuada, por cuatro o cinco días consecutivos sólo por hombres entre los de Patagonia y por todo el grupo familiar entre los grupos del Chaco (Dobrizhoffer 1969:223; Paucke 1943:180; Schmid 1964:30); (c) los asentamientos transitorios donde permanecían un día o una noche cuando los traslados eran largos y rápidos, por motivos comerciales o por movimientos estacionales (Dobrizhoffer 1968:120; Viedma 1972:922-933); (d) los grandes asentamientos múltiples (en el sentido de reunir grupos étnicos que se 
identificaban como diferentes o, por lo menos, respondían a diferentes caciques), con gran cantidad de unidades familiares que se reunían durante la primavera o el verano, por motivos económicos o políticos, preferentemente en territorios de contacto entre unos grupos y otros (Musters 1979:222). Entre los grupos abipones no fue posible hallar estos indicios antes del período reduccional (Lucaioli 2005); los encuentros para establecer alianzas o realizar intercambio de bienes que se mencionan después de instaladas las reducciones no permiten suponer, según la autora, que fueran una práctica previa resignificada. Entre los mocovíes, Nesis (2005) encuentra que el despliegue de actividades rituales que congregaba a una gran cantidad de grupos al mismo tiempo en la primavera, sí podía dar lugar a este tipo de asentamiento.

Los ciclos anuales que se pueden identificar en los grupos del Chaco con algo más de seguridad permiten considerar en su real dimensión algunos indicios que se presentan para Patagonia. Reuniendo los datos de ambas regiones, podemos afirmar que los ciclos anuales de movilidad les permitían explotar diferentes recursos: en el invierno se dispersaban en grupos pequeños de sólo unas 50 personas y se dedicaban a la caza en territorios separados para no perturbarse, y en primavera y verano se reunían 200 o más unidades familiares (aproximadamente 2.000 personas para el caso de Patagonia) en espacios acordados previamente; allí intercambiaban bienes, se dedicaban a la recolección de algunos vegetales o frutos $\mathrm{y}$ al consumo en conjunto de las bebidas que obtenían de ellos o resolvían cuestiones políticas y sociales, como alianzas o matrimonios.

En cuanto a la relación de la condición de nómades de estos grupos con la fórmula caza-salvajismo-falta de previsión, es un planteo que perduró en la bibliografía etnográfica de Patagonia hasta la década de 1980. Pero, para el Chaco, aún hoy algunos autores mencionan una ausencia de planificación (Santamaría 1999:181) en un medio ambiente con escaso potencial económico que no permitiría la reunión de grupos por períodos prolongados (Saeger 2000:8). Estas concepciones responden a un modelo de nomadismo que ha sido profundamente replanteado, principalmente desde la arqueología. Desde fines de la década de 1960, los arqueólogos han reformulado la noción del nomadismo entre los cazadores recolectores
(Lee y De Vore 1968) y en la de 1980 han introducido el concepto de "intensificación”. Se habla de intensificación, por ejemplo, cuando se produce un mayor conocimiento del ciclo vital de las especies o se manipulan los recursos de modo que aumente su rentabilidad. Algunos autores definen el proceso de intensificación como un aumento del trabajo o la introducción de alguna tecnología capaz de acrecentar la producción más allá de las necesidades básicas de subsistencia (Zvelebil 1986, citado por González 2005). Para el caso de los grupos mocovíes, ya antes de su establecimiento en reducciones, durante los primeros años del siglo XVIII encontramos indicios que dan cuenta de un proceso de intensificación: preparación de diversos alimentos secos como charque (carne salada y secada al sol), langostas tostadas y frutas desecadas para su almacenaje y harinas de diversos frutos como la algarroba, según relata Paucke (1944:239-241). Además, contaban con elaborados sistemas de almacenaje y transporte construidos con maderas, fibras vegetales y cueros. Por lo tanto, deberíamos pensar que estos grupos habían desarrollado diferentes estrategias para hacer frente a posibles situaciones de escasez.

Para los grupos tehuelches y abipones, es posible reconstruir el alto grado de previsibilidad que tenían sus movimientos a través de rutas conocidas, buscando paraderos que identificaban con nombres propios, anticipando su presencia en determinadas regiones con mucha antelación y planeando la obtención de determinados recursos económicos, saqueos e intercambios que fueron el eje de su economía (y se intensificaron notablemente con la incorporación del caballo) o acciones guerreras, pactos y alianzas en el plano político (Nacuzzi 1991; Nacuzzi y Pérez de Micou 1994). El nomadismo puede ser visto, entonces, como una estrategia económica que buscaba maximizar las posibilidades económicas y no estaba restringido a las actividades de caza (Lucaioli 2005).

Hay aun otro supuesto en alguno de los autores que se han ocupado de las poblaciones históricas del Chaco recientemente. La explotación del medio ambiente por parte de los grupos nativos sería no intensiva y, por lo tanto, "armónica" en oposición a la explotación intensiva que impuso la sociedad blanca, por lo que se define la situación como de "lógicas contrapuestas" (Paz 2003:379). Parece haberse dado más bien una complementariedad en cuanto a la explotación e inter- 
cambio de recursos económicos en la que los indígenas habrían ocupado el lugar de abastecedores de ganado, cueros, plumas, miel -entre otros productos- en amplias redes comerciales que conectaban diferentes puntos de la economía colonial entre sí, a través de los espacios chaqueño y pampeano-patagónico.

\section{La Adopción de Bienes Exóticos}

Defino el concepto de complementariedad como la posibilidad que algunos de los grupos tenían de acceder a bienes que no producían por sí mismos a cambio de otros más accesibles o que podían producir con excedente. Muchas veces se daba una tercerización: grupos que obtenían -por intercambio- bienes que no producían, pero no lo hacían para consumirlos o utilizarlos, sino para entregarlos a otros grupos que los demandaban. Con el ingreso de bienes exóticos a los circuitos económicos indígenas, estas acciones de intercambio y tercerización aumentaron notablemente, aparte de que había aparecido un nuevo sujeto en la demanda: la sociedad colonial. Veamos algunos ejemplos.

Los indios del norte de la Patagonia les vendían a los españoles del Fuerte del Río Negro ganado vacuno y caballar robado en los campos de Buenos Aires. Recibían a cambio: harina, tabaco, aguardiente, bayeta, sombreros, yerba mate. Estos mismos indios recibían en Valdivia frenos, cuchillos y lanzas a cambio de ponchos que, a su vez, obtenían de otros grupos, los aucas o mapuches de la Pampa. Además, por caballos y cueros de guanaco podían obtener piñones y ovejas que criaban grupos más sedentarios como los pehuenches de Neuquén. Los grupos tehuelches de más al sur les entregaban cueros de guanaco (muchas veces de guanaco nonato) a cambio del preciado caballo que, entre ellos, usaban muy pocos personajes (Nacuzzi 2000). El intercambio entre diferentes grupos indígenas era de un volumen considerable en el norte de la Patagonia y vemos que algunos de estos cazadores no dudaban en sacrificar hembras preñadas para responder a la demanda de las ciudades, puesto que allí eran finalmente entregados los cueros de guanaco nonato (Nacuzzi 1998, 2000).

Los indios del Chaco entregaban a los misioneros jesuitas caballos a cambio de agujas, cuchillos, anzuelos, tabaco, pan y yerba mate (aunque esta planta era autóctona para la región y podían acceder a ella con relativa facilidad). El jaguar (como el guanaco nonato) tenía una notable demanda en las ciudades que bordeaban el espacio indígena de abipones y mocovíes. Tanto, que sus pieles (que integraban el precio de la novia) se comenzaron a utilizar para el intercambio y en el precio de la novia comenzaron a aparecer caballos (Lucaioli 2005; Nesis 2005).

Hasta aquí se ha descrito un intercambio que podríamos llamar espontáneo. Cuando los mocovíes y abipones fueron reducidos en pueblos, desarrollaron nuevas prácticas económicas. Algunas estuvieron relacionadas con la subsistencia y otras con el intercambio comercial que desarrollaban en las ciudades aledañas. De hecho, las reducciones facilitaron la comercialización de algunos productos (ganado en pie, cueros, miel, plumas) a la vez que permitieron el desarrollo de nuevas actividades comerciales y productivas, como ya hemos mencionado (la cría de ovejas, el cultivo de trigo y algodón, etc.). Para la región pampeana, Mandrini (1985) ha descrito el "ciclo del toldo" y el "ciclo del ganado" que abastecían la economía doméstica y la del intercambio, respectivamente, y dan por supuesto la generación de un excedente en la producción. Para el Chaco, Saeger (2000) menciona un mercado local y otro regional que se amplió ante las demandas de la sociedad hispanocriolla. A su vez, Paz (2003), contradiciéndose en cuanto a su postulado de una economía restringida por las condiciones ambientales mencionado más arriba, sostiene que los grupos del Chaco participaban de amplias redes comerciales gracias a que el aprovechamiento de los recursos cubría sus necesidades de subsistencia y generaba un excedente.

Especial atención merece el caballo que hizo posible para ambos grupos indígenas una mayor movilidad, más facilidad para la caza de animales y la realización de malones y un efímero mejoramiento de la vida cotidiana. También les habría permitido desarrollar una fuerte resistencia frente a las presiones coloniales (Schindler 1985).

La literatura antropológica norteamericana acuñó la expresión horse complex que se generalizó para describir la adopción del caballo y un complejo de rasgos asociados por parte de los cazadores recolectores de diferentes áreas del mundo. Palermo (1986) criticó la aplicación de este modelo -que sirvió para explicar una transforma- 
ción total de la cultura- a los cazadores recolectores del extremo sur americano. Señaló tres motivos que habían facilitado la importación del concepto: el desconocimiento de los rasgos orgánicamente asociados a la vida ecuestre, el desconocimiento de los contextos económicos específicos que acompañaron la adopción del caballo en los diferentes grupos y la falta de una discusión acerca de la pertinencia de describir un "complejo ecuestre" para la región sudamericana. Ahora estamos avanzando notablemente en el estudio de los dos primeros ítems.

En cuanto a los rasgos asociados a la adopción el caballo, podemos mencionar, por ejemplo, las ventajas que adquirieron los grupos en la movilidad y en los desplazamientos. Pudieron recorrer áreas mucho más extensas en tiempos más cortos y trasladar un volumen considerable de bienes para el intercambio. Estos aspectos están bien documentados para los siglos XVIII y XIX en el norte de Patagonia, donde el caballo les permitió desplazamientos tan amplios como los que realizaban desde regiones muy cercanas a la Cordillera hasta los campos de Buenos Aires (Nacuzzi 1998). Entre los grupos del sur de Patagonia, los caballos eran menos numerosos, pero ellos también realizaban incursiones desde San Julián, por ejemplo, hasta Buenos Aires y su rica zona de ganado cimarrón (Nacuzzi 1991; Viedma 1972). Los bienes requeridos por las colonias españolas -sobre todo cueros- eran cargados y trasladados a caballo. En los movimientos realizados por un número considerable de individuos para trasladar un campamento, por ejemplo, el caballo servía para cargar la vivienda desarmada y todos los enseres domésticos y, a la vez, la caravana de mujeres y caballos cargados participaban del cerco que facilitaba a los cazadores, también montados, encerrar a las presas de caza (Musters 1979:130-131). Además del incremento en el número de presas cazadas, el caballo posibilitaba realizar malones y saqueos sorpresivos para conseguir más caballos o ganado vacuno (Cartas y Diarios inéditos varios, citados por Nacuzzi 1998:142-158) y, quizás lo más importante entre los grupos del norte de Patagonia, arrear ese ganado por rutas muy conocidas hacia grupos intermediarios que estaban cercanos a la Cordillera (Cartas y Diarios inéditos varios, citados por Nacuzzi 1998:151-154). Estas actividades tal vez los pusieron en contacto con grupos -indígenas, españoles o criollos- que no conocían antes de adquirir esa facilidad en sus desplazamientos, lo que les debe haber permitido establecer nuevas relaciones interétnicas. Poseer caballos era también una señal de prestigio y el mejor ejemplo es que entre los del sur de Patagonia -donde los caballos escaseaban- estos animales estaban reservados para los caciques (Viedma 1972). La carne de yeguas se consumía al principio en ceremonias que se realizaban por el ingreso a la pubertad de las jóvenes o por la celebración de matrimonios, aunque luego su ingesta podría haber sido más generalizada. Ante la demanda de cueros de guanaco por los mercados coloniales, el cuero de caballo lo reemplazó en la confección de la vivienda, al tiempo que aparecieron riendas, lazos, cinchas y "botas" confeccionadas con cuero de caballo, más otras manufacturas como los estribos y la montura de madera o las cunas de caña para transportar a los niños a caballo (Musters 1979:239-240, 243, 245). Esta gran cantidad de nuevas manufacturas relacionadas con el uso del caballo fueron, sin dudas, las que pesaron en la bibliografía clásica para alentar la mención de un "complejo ecuestre", aunque los mismos cronistas que describen estas novedades mencionan, por ejemplo, que debajo de la montura de madera se usaba una piel de guanaco o un poncho (es decir, un elemento que formaba parte de su ajuar ancestral o uno que debían adquirir entre grupos que tejían, como los aucas o mapuches).

Para los grupos del Chaco, algunos autores sostienen que "la introducción del caballo promovió la formación de conjuntos culturalmente semejantes" (Braunstein 1983:21) y otros, que desarrollaron una "cultura del caballo" similar a la de los indios de las planicies de Norteamérica o a la de los mapuches de Chile (Saeger 2000:7). Por un lado, los grupos que adoptaron el caballo en América del Sur no conformaron conjuntos culturalmente semejantes, como veremos al comparar a los de Patagonia con los del Chaco; tal vez lo que les dio un aire de familia es que ambos grupos eran cazadores recolectores en el momento en que el caballo llegó a sus vidas. En cuanto a los indios de las planicies norteamericanas, ellos se pueden comparar más estrechamente con los de Patagonia que con los del Chaco. Además, estos últimos sólo compartían con los mapuches -hablando de rasgos asociados al caballo- la práctica de realizar malones o acciones guerreras. En estas consideraciones quizás pese demasiado la descripción 
de estos grupos como poseedores de un fuerte "ethos guerrero" (Saeger 2000; Susnik 1981).

Entonces, ¿qué rasgos se asociaron a la adopción del caballo entre los grupos del Chaco en el siglo XVIII? En principio, la caza no se vio favorecida, dadas las características ecológicas del ámbito chaqueño: las áreas pantanosas y la densidad de la vegetación dificultaron la caza a caballo, pero habría facilitado el transporte de las presas y la realización de saqueos y malones (Schindler 1985), como también una movilidad más amplia y el establecimiento de tratos comerciales con diferentes grupos indígenas o criollos (Nesis 2005). Como entre los grupos de Patagonia, algunos incorporaron el caballo sólo como animal de carga porque era un bien escaso, y otros pudieron usarlo para otras actividades económicas y de la vida social (Schindler 1985). También los grupos mocovíes y abipones se insertaron en el mercado colonial comerciando caballos y vacas (Lucaioli 2005; Nesis 2005); para estos grupos, los autores destacan el fuerte entrelazamiento entre la adopción del caballo, el ganado vacuno y el hierro (Lucaioli 2005), una ventaja para la caza proporcionada por el caballo y el hierro (Saeger 2000) y un aumento en el consumo de carne por la incorporación del ganado vacuno en detrimento de los recursos obtenidos por recolección (Lucaioli 2005). Este fenómeno ocurrió también entre los grupos del sur de Patagonia: ellos no consumían vacas pero incrementaron la obtención de carne de guanaco y, aparentemente, dejaron de elaborar harinas (Boschín y Nacuzzi 1979). Otra cuestión similar es la fuerte demanda desde el mercado hispanocriollo de pieles (de jaguar en el caso del Chaco y de guanaco en Patagonia). Entre los mocovíes, las pieles de jaguar integraban tradicionalmente el precio de la novia y fueron remplazadas por caballos para responder a la demanda externa y porque los caballos estaban disponibles en número considerable (Nesis 2005). En el caso de los abipones, las fuentes directamente informan que el precio de la novia estaba compuesto por caballos, vestidos de lana, lanzas con punta de hierro y otros bienes exóticos (Lucaioli 2005). El guanaco y el jaguar, entonces, sufrieron una matanza indiscriminada. Para el Chaco, algunos autores mencionan que hacia el siglo XVIII se quebró el equilibrio ecológico (Saeger 2000) o que especies como el ciervo habrían llegado a su casi total extinción como consecuencia de la intensificación de la caza para el abastecimiento colonial (Susnik 1973). Para Pata- gonia, la demanda de pieles de guanaco nonato hizo que estos grupos -tradicionalmente cazadores que deberían cuidar a las hembras preñadasolvidaran cuidados elementales para la preservación de la reproducción de los animales que les servían de sustento y, para los especialistas, quedaran oscurecidas ciertas menciones que podrían hacer pensar en los primeros pasos hacia la domesticación, como el uso de guanacos pequeños como señuelo para la caza (Boschín y Nacuzzi 1979, Nacuzzi 1998). Estos problemas ecológicos -y económicos- requieren estudios más especializados e interdisciplinarios.

En cuanto a los contextos económicos que acompañaron la adopción del caballo, podemos diferenciar algunas situaciones. Entre los grupos cazadores recolectores de Patagonia, que nunca estuvieron reducidos, el caballo fue muy importante en su economía. Ellos estaban habituados a movilizarse por su hábitat para explotar más provechosamente los recursos económicos disponibles y, en un principio, el caballo les permitió mejorar esa movilidad. Un segundo paso sería el de la preponderancia de la caza-que resultaba tan provechosa- y el abandono de otras actividades que requerían más tiempo y proporcionaban menos beneficios, como la recolección. Un tercer paso sería el cambio de las actividades tradicionales -incluida la caza- para dedicarse a proveer a los mercados coloniales de los bienes que ellos requerían, obteniendo esos bienes de otros grupos, indígenas o no. Pudo haber una división de tareas entre diferentes grupos. Como lo ha señalado Moore (1987), los cheyenne de las praderas norteamericanas orientaban las actividades económicas de tres de sus bandas a la obtención de pieles de castor, la de caballos y la producción de prendas de vestir. Esto puede equipararse con las actividades que realizaban los grupos cercanos al Fuerte del Carmen a fines del siglo XVIII: los aucas proveían ponchos y productos agrícolas, los pampas ofrecían ganado y los más lejanos tehuelches, pieles de guanaco (Nacuzzi 1998).

Con la adopción del caballo abipones y mocovíes ampliaron sus circuitos de desplazamiento (Lucaioli 2005). Esto les permitió incorporar el ganado vacuno a su dieta y el hierro a sus bienes. El hecho de disponer con seguridad de una cantidad de cabezas de ganado vacuno y caballar periódicamente debe haber sido un factor de peso para que se avinieran a la vida en pueblos de reducción (Saeger 1985, 2000), aunque el hecho de 
vivir en reducciones no les impidió participar también de saqueos y malones para conseguir ganado. Nesis (2005) plantea que, siendo la reducción una prestación defensiva para la ciudad que estaba más cercana, hubo un condicionamiento sobre el tipo de adoctrinamiento posible para estos indios, puesto que era necesario conservar sus hábitos guerreros. Aunque también la presencia de los misioneros y las continuas quejas de las ciudades vecinas por las violentas incursiones, deben haber jugado un papel moderador. De todas maneras, en el ámbito de la reducción los jesuitas alentaron la incorporación de nuevas prácticas económicas (y ellas acrecentaron la inserción de estos grupos en el mercado) tales como la cría de ovejas y el uso de su lana para realizar mantas (Lucaioli 2005; Nesis 2005). Otras prácticas nuevas como el cultivo del trigo y el algodón entre los mocovíes (Nesis 2005) o tradicionales como la recolección de miel y la pesca entre los abipones (Lucaioli 2005) parecen haberse mantenido para cubrir las necesidades internas de los pueblos reducidos.

Habría que analizar con más profundidad si esta función defensiva de los pueblos de reducción no condicionaba la cantidad de ganado que estos grupos "podían" conseguir y si ese ganado no era sólo el necesario para poder mantener sus actividades y/o proveerse de un nuevo número acotado de cabezas de ganado que les permitiera retroalimentar su propio circuito de saqueo-defensa-intercambio/abastecimiento de la reducción. Lucaioli y Nesis (2005) afirman que el ganado que entregaban las ciudades o los jesuitas funcionaba como señuelo para mantenerlos reducidos y disminuir las partidas de caza, esos animales eran preferiblemente vacas. En cuanto a los caballos, Paucke (misionero entre los mocovíes) disponía de muchos de ellos y Dobrizhoffer (misionero entre los abipones) se quejaba por su escasez. Si pensamos que los mocovíes habían resultado más receptivos a las nuevas pautas económicas que les proponía la vida en reducción puesto que tejían en un volumen que les permitía participar en el mercado y practicaban la agricultura de trigo y algodón (Nesis 2005) y los abipones, en cambio, criaban ovejas pero no producían para el mercado y descuidaban continuamente sus cultivos (Lucaioli 2005), podría ser factible mi hipótesis de que la entrega de ganado era manipulada de alguna forma -por los misioneros o por los agentes del estado colonial- de manera que resultara un "premio" para los grupos más dóciles, o que sólo alcanzara para asegurar la protección de la ciudad vecina y el abastecimiento de la reducción, manteniendo los niveles de conflicto bélico interétnico razonablemente controlados. En el caso del Fuerte del Carmen de la costa patagónica, la protección por parte de los indios vecinos se traducía en el aprovisionamiento de cabezas de ganado que aseguraba la subsistencia de los españoles; aunque también es posible que la presencia de caciques amigos acampando cerca de fuerte lo hayan preservado de ataques de otros caciques u otros grupos indígenas (Nacuzzi 1998:223).

La interpretación que hacen Lucaioli y Nesis (2005) acerca de la disminución de las partidas de caza y sus motivos se contrapone a la afirmación de Santamaría $(1999,2000)$, para quien la inserción en el Chaco del ganado vacuno y ovino provocó un desplazamiento de la fauna autóctona a zonas más alejadas y un descenso en las actividades de caza tradicionales y en el uso de la carne de animales salvajes como alimento. La explicación más sencilla es la que proponen Lucaioli y Nesis (2005): estos grupos comenzaron a tener un acceso más fácil a otros bienes que garantizaban la subsistencia y a los jesuitas les interesaba disminuir las salidas en partidas de caza.

La apropiación violenta de ganado -el malónocurría cuando no se cumplían las entregas por parte de los misioneros o de las ciudades de Santa Fe o Asunción. Los motivos de la realización de malones en la frontera sur de Buenos Aires parecen no estar tan bien identificados, aunque habría que tener en cuenta la hipótesis de Crivelli Montero (1991) en el sentido que estos ataques podían estar forzando acuerdos de paz en los que siempre se establecían raciones que incluían bienes muy preciados para los grupos que pactaban el acuerdo. En el caso de la frontera de Santa Fe, los acuerdos fueron previos al establecimiento de la reducción y los vecinos se comprometieron a entregar una cantidad de cabezas de ganado por mes ante el compromiso de los indios de dejar de realizar malones en las estancias vecinas (Nesis 2005). Aunque siempre tendremos que tener en cuenta la misma demanda del fuerte (en Patagonia) o de las ciudades (en el litoral del Paraná) como motivo para esta apropiación violenta de animales en otras jurisdicciones; el circuito de apropiación y comercialización se retroalimentaba constantemente (Palermo 1991). Las autoridades coloniales vieron con constante preocupación el hecho de que tanto los vecinos de las ciudades vecinas a las re- 
ducciones como los pobladores de los fuertes recibieran y consumieran el ganado robado. Esos intercambios ventajosos para algunos, significaban el aumento de las hostilidades y amenazas para otros poblados españoles.

El malón también constituía una forma de debilitamiento del otro, ya que combinaba las necesidades económicas con las aptitudes y el poderío bélico. Según Boccara (1998:275), el malón como una forma de guerra posible se cristalizó en un complejo económico-bélico que puede entenderse en dos dimensiones: como forma institucionalizada de abastecimiento e intercambio y como una manera de mantenimiento de la autonomía política de los grupos indígenas frente a las presiones coloniales.

Durante los malones, los grupos indígenas obtenían ganado, armas y cautivos. La circulación de cautivos y su fuerza de trabajo era otro de los beneficios del malón. Muchos cautivos se incorporaron a la vida entre los indios, aunque lo hicieron con estatus diferentes. En el sur, los cautivos llegaron a adquirir lugares importantes en la sociedad indígena: en el caso de las mujeres, a través del casamiento con caciques o personajes de prestigio; en el de los varones, oficiando de lenguaraces, secretarios, etc. En cambio, entre los mocovíes del Chaco los cautivos estaban segregados del resto del grupo, junto con otros mocovíes que alguna vez habían sido cautivos de los españoles y no existía el casamiento con mujeres cautivas (Nesis 2005). Entre los abipones, los hombres cautivos -españoles o de otros grupos étnicospodían adquirir prestigio y transformarse en líderes y casarse con alguna mujer respetable del grupo indígena; para las mujeres cautivas era imposible tanto el casamiento como el cambio de estatus (Lucaioli 2005).

\section{Consideraciones Finales}

En el siglo XVIII había pueblos del extremo sur de América que no habían sido sometidos aún al control del estado colonial y esto se debió, fundamentalmente, a su condición de nómades. Tanto en el norte de Patagonia como en el sur del Chaco, los grupos indígenas conservaron gran parte de su autonomía. Ello dependió, en parte, de sus aptitudes y estrategias grupales y, en gran parte también, de las necesidades de la población blanca. Sobre todo en el Chaco, las reducciones de gru- pos indígenas actuaron como aparato de defensa de ciertas ciudades ante los ataques de otros grupos indígenas, por lo que a cada ciudad le convenía (en desmedro de otras) que eventualmente permanecieran moviéndose por el espacio chaqueño y abandonaran periódicamente los pueblos de reducción. Los misioneros alentaron entre los grupos indígenas ciertas pautas económicas que suponían una forma de vida más "civilizada", tales como la cría de animales y la agricultura, aunque les otorgaban permiso para continuar cazando. Con esto, les brindaban además la posibilidad de ir a aprovisionarse de caballos y vacas en jurisdicciones de ciudades vecinas y obtenían un reaseguro defensivo ante posibles incursiones sobre la ciudad que protegían. En Patagonia, el Superintendente del Fuerte del Carmen estableció una fluida relación con los caciques que se fueron presentando y lo aprovisionaban de ganado a cambio de otros bienes muy apreciados por los indígenas, lo que constituía una defensa implícita a los tan temidos ataques.

Estos pueblos nómades habían ampliado considerablemente los territorios que visitaban gracias a la incorporación del caballo y se habían relacionado exitosamente con otros pueblos indígenas, con los que intercambiaban una amplia variedad de bienes. También sostuvieron una relación casi armoniosa con algunas colonias y enclaves españoles y, como queda claro con los ejemplos de los grupos de Patagonia, habían reformulado sus circuitos de movilidad en razón de estas nuevas relaciones.

La incorporación de nuevos bienes incluyó, además de caballos y vacas, hierro, armas, tabaco, azúcar, harina, telas y mantas tejidas, ponchos, productos agrícolas y objetos de prestigio como sombreros y bastones de mando. Las nuevas relaciones interétnicas también implicaron una reformulación de los espacios que ocupaban: la reducción fue un espacio acotado, no elegido libremente, pero al cual entraban y salían con bastante autonomía y porque les resultaba conveniente. El fuerte atrajo a diversos grupos a acampar en sus inmediaciones porque los intercambios que se podían negociar en él resultaban convenientes. Ambas situaciones señalan nuevos espacios en un paisaje muy conocido o, por lo menos, espacios utilizados de manera diferente, o compartidos con los blancos.

La obtención de recursos económicos también fue reformulada a partir de los requerimientos de los nuevos vecinos, fueran españoles o indígenas. 
Cueros, pieles, mantas y plumas comenzaron a ser obtenidos con excedente para el intercambio. Nuevos bienes comenzaron a ser requeridos para cubrir la demanda de otros grupos, como los cueros de guanaco que los pampas y aucas obtenían de los tehuelches para poder ofrecer en Buenos Aires. Esto implicó, por parte de casi todos los grupos, una readaptación de las pautas económicas previas para estar en condiciones de ofrecer los bienes que les demandaba el mercado (colonial o indígena). En este sentido, el malón fue una importante empresa económica que les proporcionaba caballos, vacas, armas y cautivos.

Los grupos indígenas fueron intermediarios siempre requeridos por la sociedad blanca (desde las reducciones o desde un puesto fronterizo como el fuerte). Ellos presentaban a otros grupos, transmitían información, describían el territorio. También se destacaron como negociadores de ayudas económicas y políticas, de acuerdos de paz, de devolución de cautivos. Finalmente, brindaron y exigieron servicios. El más destacado, el de defensa de pueblos y estancias a cambio del ganado que les permitía retroalimentar el circuito de in- tercambios, desplazamientos, información, obtención y traslado de bienes, malones, cautivos, armas, ganado.

Esta reflexión comparativa aporta en sí misma nuevos datos para tener en cuenta en futuros estudios de las regiones tratadas y, sobre todo, para algunos ítems que continúan siendo problemáticos, tales como la identificación de grupos étnicos, el papel de los bienes europeos en su economía y la verdadera dimensión del nomadismo. En el futuro, deberíamos incorporar a esta reflexión otros aspectos de la vida social y política de estos grupos y abarcar en ella a otros cazadores recolectores del mundo.

Agradecimientos: La primera versión de este trabajo fue una conferencia en el Centro de Estudios Históricos de Madrid (CSIC), en junio de 2005. Agradezco a los evaluadores del mismo las valiosas sugerencias propuestas. Proyectos de investigación financiados por el Consejo Nacional de Investigaciones Científicas y Técnicas (PIP 5567) y la Universidad de Buenos Aires (UBACyT F 016).

\section{Referencias Citadas}

Boccara, G.

1998 Guerre et Ethnogenése Mapuche dans le Chili Colonial. L' Harmattan, París.

2000 Antropología diacrónica. Dinámicas culturales, procesos históricos y poder político. En Lógica Mestiza en América, editado por G. Boccara y S. Galindo, pp. 21-59. Instituto de Estudios Indígenas, Universidad de La Frontera, Temuco.

Boschín, M. y L. Nacuzzi

1979 Ensayo metodológico para la reconstrucción etnohistórica. Su aplicación a la comprensión del modelo tehuelche meridional. Serie Monográfica 4. Colegio de Graduados en Antropología, Buenos Aires.

Braunstein, J.

1983 Algunos Rasgos de la Organización Social de los Indígenas del Gran Chaco. Facultad de Filosofía y Letras, Buenos Aires.

Canals Frau, S.

1973 Poblaciones Indígenas de la Argentina: su Origensu Pasado - su Presente. Editorial Sudamericana, Buenos Aires.

Casamiquela, R.

1985 Bosquejo de una Etnología de la Provincia de Río Negro. Fundación Ameghino, Viedma.

Crivelli Montero, E.

1991 Malones: ¿saqueo o estrategia? El objetivo de las invasiones de 1780 y 1783 a la frontera de Buenos Aires. Todo es Historia 283:6-32.
Dobrizhoffer, M.

1968 Historia de los Abipones II. Universidad Nacional del Nordeste, Resistencia.

1969 Historia de los Abipones III. Universidad Nacional del Nordeste, Resistencia.

Escalada, F. 1949 El Complejo "Tehuelche”. Estudios de Etnografía Patagónica. Coni, Buenos Aires.

González, M.I.

2005 Arqueología de Alfareros, Cazadores y Pescadores Pampeanos. Sociedad Argentina de Antropología, Buenos Aires.

Gruzinski, S. 1999 La Pensée Métisse. Fayard, París.

Kersten, L.

1968 Las Tribus Indígenas del Gran Chaco hasta Fines del Siglo XVIII. Universidad Nacional del Nordeste, Resistencia.

Lee, R. e I. De Vore, editores 1968 Man the Hunter. Aldine, Chicago.

Lucaioli, C. 2005 Los Grupos Abipones hacia Mediados del Siglo XVIII. Sociedad Argentina de Antropología, Buenos Aires.

Lucaioli, C. y F. Nesis

2005 El ganado de los grupos abipones y mocoví en el marco de las reducciones jesuitas (1743-1767). Andes, en prensa. 
Mandrini, R.

1985 La sociedad indígena de las pampas en el siglo XIX. En Antropología, compilado por M. Lischetti, pp. 205-230. EUDEBA, Buenos Aires.

Moore, J.

1987 The Cheyenne Nation. A Social and Demographic History. University of Nebraska Press, Lincoln/Londres.

Musters, G.

1979 Vida entre los Patagones. Solar-Hachette, Buenos Aires.

Nacuzzi, L.

1991 La cuestión del nomadismo entre los tehuelches. Memoria Americana 1:103-134.

1998 Identidades Impuestas. Tehuelches, Aucas y Pampas en el Norte de la Patagonia. Sociedad Argentina de Antropología, Buenos Aires.

2000 El papel de los contactos intergrupales en el abastecimiento de recursos en Patagonia, siglo XVIII. Arqueología 10:121-134.

2002 Los grupos, los nombres, los territorios y los blancos: historia de algunos nombres étnicos. En Colonización, Resistencia y Mestizaje en las Américas, editado por G. Boccara, pp. 259-289. Abya-Yala/IFEA, Quito/Lima. 2005 El queso y los gusanos en el extremo sur de América. Grupos étnicos, disputas académicas y un juicio por registro de marca. Revista de Indias LXV (234):427-452.

Nacuzzi, L. y C. Pérez de Micou

1994 Rutas indígenas y obtención de recursos económicos en Patagonia. Memoria Americana 3:91-103.

Nesis, F.

2005 Los Grupos Mocoví en el Siglo XVIII. Sociedad Argentina de Antropología, Buenos Aires.

Palermo, M.A.

1986 Reflexiones sobre el llamado "complejo ecuestre" en la Argentina. Runa XVI:157-178.

1991 La compleja integración hispano-indígena del sur argentino chileno durante el período colonial. América Indígena LI (1):153-192.

Paucke, F.

1943 Hacia Allá y para Acá. Una Estadía entre los Indios Mocobíes, 1749-1767 II. Universidad Nacional de Tucumán, Tucumán.

1944 Hacia Allá y para Acá. Una Estadía entre los Indios Mocobíes, 1749-1767 III. Universidad Nacional de Tucumán, Tucumán.

Paz, C.

2003 "Cómo es su costumbre hacer casi cada año ...". Algunas consideraciones sobre las actividades económicas de los pueblos del Gran Chaco argentino, Siglo XVIII. En Las Fronteras Hispanocriollas del Mundo Indígena Latinoamericano en los Siglos XVI-XIX, compilado por R. Mandrini y C. Paz, pp. 377-405. CEHIR/UNS/Instituto de Estudios Histórico Sociales, Tandil.
Pratt, M.

1997 Ojos Imperiales. Literatura de Viajes y Transculturación. Universidad Nacional de Quilmes, Bernal.

Quijada, M.

2002 A modo de epílogo. En Funcionarios, Diplomáticos, Guerreros. Miradas hacia el Otro en las Fronteras de Pampa y Patagonia (Siglos XVIII y XIX), compilado por L. Nacuzzi, pp. 287-293. Sociedad Argentina de Antropología, Buenos Aires.

Saeger, J.

1985 Another view of de mission as a frontier institution: the guaycuruan reductions of Santa fe, 1743-1810. The Hispanic American Historical Review 65:493-517.

2000 The Chaco Mission Frontier. The Guaycuruan Experience. The University of Arizona Press, Tucson.

Sánchez Labrador, J.

1936 Los Indios Pampas-Puelches-Patagones. Viau y Zona, Buenos Aires.

Santamaría, D.

1999 Población y economía interna de las poblaciones aborígenes del Chaco en el siglo XVIII. Andes 9:173-195.

2000 La sociedad indígena. En Nueva Historia de la Nación Argentina II. Planeta, Buenos Aires.

Schindler, $\mathrm{H}$.

1985 Equestrian and not equestrian Indians of the Gran Chaco during de colonial period. Indiana 10:451-464.

Schmid, T.

1964 Misionando por Patagonia Austral. Academia Nacional de la Historia, Buenos Aires.

Susnik, B.

1971 Dimensiones migratorias y pautas culturales de los pueblos del Gran Chaco y su periferia (enfoque etnológico). Suplemento Antropológico 7 (1):85-107.

1981 Etnohistoria de los Chaqueños (1650-1910). En Los aborígenes del Paraguay. Museo Etnográfico "Andrés Barbero", Asunción.

Viedma, A.

1972 Diario y Descripción de la costa meridional del sur llamada vulgarmente patagónica. En Colección Pedro de Angelis VIII B, pp. 845-963. Plus Ultra, Buenos Aires.

Vignati, M.

1941 Contribución a la etnobotánica indígena: el "pan" de los Patagones protohistóricos. Notas del Museo de La Plata 6, Antropología 23:321-336.

Wachtel, N.

1978 La aculturación. En Hacer la Historia I, editado por J. Le Goff, J. y P. Nora, pp. 135-156. Laia, Barcelona.

White, R.

1991 The Middle Ground: Indians, Empires and Republics in the Great Lakes Region, 1650-1815. Cambridge University Press, Cambridge. 